\title{
Tribuna: Més grata que els estels. Pasqual I i la Roma del Seu temps
}

\section{Carles Mancho}

Institut de Recerca en Cultures Medievals (IRCVM)

Universitat de Barcelona

e-mail: carles.mancho@ub.edu

doi: $10.1344 /$ Svmma2017.9.2

Esteve IV moria a Roma el 24 de gener del 817. El seu regnat, iniciat amb la consagració del 22 de juny del 816, suposa una breu pausa després dels llargs i intensos regnats d'Hadrià I (772795) i Lleó III (795-816). A finals de gener del 817 pujava al soli pontifici Pasqual I; enguany fa 1200 anys. Si els pontificats dels predecessors havien permès la reorganització administrativa i econòmica de la que ha estat molt encertadament anomenada "Republica de San Pere" i en particular de la ciutat de Roma, sens dubte, els convulsos set anys del regnat de Pasqual I -mor entre febrer i maig del 824- van ser els de la transformació de la ciutat. Una transformació que cal interpretar seguint, com a mínim, dues coordenades. D'una banda, hi ha la ciutat remonumentalitzada; la ciutat que físicament veu transformats alguns dels edificis més notables, com ara Sant Pere al Vaticà o Santa Maria la major, però sobretot veu aparèixer els nous edificis, encara conservats, de Santa Praxedis a l'Esquilí, Santa Maria in Domnica i Santa Cecilia al Trastèvere. Fins ara ens hem interrogat ben poc sobre les causes d'aquesta conservació a través del segles; conservació que no només es refereix a les fàbriques sinó sobretot a les decoracions. Ens atreviríem a dir que és gairebé insòlit i tot i que l'esperit de la contrareforma de segur que hi va tenir molt a veure, no deixa de ser un fet singular. Aquells nous edificis van canviar sens dubte la percepció de la ciutat tant dels romans com dels forasters.

De l'altra banda, però, hi ha la ciutat que canvia conceptualment. Prou que se n'ha escrit sobre el gran trasllat dels 2300 (dos-mil tres-cents) cossos de màrtirs exhumats a les catacumbes i de nou sebollits a dins Santa Praxedis. Els autors es pregunten d'on venien els cossos, de quins màrtirs es tractava, qui va ser el primer pontífex a trencar la norma d'enterrar intra mœenia, l'estat d'ús i conservació de les catacumbes... Molt menys, gairebé gens, s'ha reflexionat sobre el canvi en el concepte de ciutat que va comportar l'adopció d'aquesta solució. De ben segur que la importància del culte a les relíquies en el món franc degué tenir un paper determinant en la decisió de Pasqual I. I també ho és que pontífex del segle VIII ja havien fet modestos trasllats tot creant els precedents. Tanmateix, el cop d'efecte de qui va prendre la decisió i l'afirmació d'autoritat que va demostrar amb aquest trasllat massiu no és negligible, ans al contrari, va servir tant per a redefinir la figura del Papa enfront dels francs -fet que es constata en molts altres 
passatges de la vida del Pontífex, des de la signatura del Hludovicianum fins l'enfrontament amb Lotari I-, i enfront de l'emperador oriental -la carta adreçada a Lleó IV sobre la querella iconoclasta és tota una declaració-, com també a redefinir Roma, l'antiga ciutat imperial, enfront de Constantinoble, la ja vella nova Roma fundada per Constantí I.

Els textos que composen aquest monogràfic de SVMMA són el resultat de l'encontre celebrat a Roma els dies 17 i 18 de novembre de 2016 sota el títol «Grata più delle stelle» S. Prassede e Pasquale I (817-824). Dialogo multidisciplinare intorno alla basilica e il suo papa, encontre que va servir per començar a donar forma a algunes de les idees que durant part del $2015 \mathrm{i}$ tot el 2016 un primer nucli d'investigadors -A. Ballardini, G. Bordi, M. Caperna, A. Verardi i qui això subscriu- anàvem desgranant mentre visitàvem els edificis de Pasqual I.

Arrel d'aquella primera trobada s'han incorporat altres investigadors -S. Ammirati, R. Michetti, R. Santangeli Valenzani- configurant, així, el Comité científic del seminari permanent sobre la figura de Pasqual I i la Roma del seu temps que es desenvoluparà entre novembre de 2017 i febrer del 2018, principalment a Roma, organitzat per la Università degli Studi Roma Tre, SapienzaUniversità di Roma i l'Institut de Recerca en Cultures Medievals (IRCVM) de la Universitat de Barcelona.

Enfront de l'esquema tradicional, ens proposem, mitjançant seminaris periòdics, de discutir pausadament sobre la importància d'aquest pontífex i les conseqüències de les seves accions a la ciutat de Roma i llurs monuments. Després d'anys de recerca i discussions creiem que és aquesta la millor manera per a proposar resultats sòlids sobre subjectes d'estudi talment complexos.

A curt termini, la publicació d'un volum amb els resultats, així com d'altres accions encara en estat embrionari, ens han de servir per a fer conèixer i aprofundir en la importància del moment històric i la interpretació que en va fer el pontífex, sens dubte determinants per a entendre l'alta edat mitjana a Roma.

Com a primer tast us deixem les cinc contribucions fruit d'aquell seminari fundacional, la finalitat de les quals és presentar alguns dels interrogants encara no resolts o encara no afrontats en la recerca sobre Pasqual I.

Un punt de partida, doncs, per a iniciar el debat.

[A seguire: testo in italiano] 


\section{Grata più delle Stelle. Pasquale I e la Roma del suo tempo}

Stefano IV moriva a Roma il 24 gennaio 817. Il suo regno, iniziato con la consacrazione del 22 giugno 816, rappresentò una breve pausa dopo i lunghi e intensi regni di Adriano I (772-795) e Leone III (795-816). A fine gennaio 817 saliva al soglio pontificio Pasquale I; quest'anno sono 1200 anni. Se i pontificati dei suoi predecessori furono l'occasione per riorganizzare l'amministrazione e l'economia della cosiddetta, in modo molto azzeccato, "Repubblica di San Pietro" e in particolar modo della città di Roma, non c'è dubbio che i convulsi sette anni del regno di Pasquale I -moriva tra febbraio e maggio 824- furono quelli della trasformazione della città. Trasformazione che bisogna interpretare seguendo, almeno, due coordinate. Da un lato, la città rimonumentalizzata. La città che fisicamente vide trasformati alcuni fra gli edifici più notevoli, come San Pietro in Vaticano o Santa Maria Maggiore, e soprattutto vide apparire i nuovi edifici, ancora conservati, di Santa Prassede all'Esquilino, Santa Maria in Domnica e Santa Cecilia in Trastevere. Finora ci siamo interrogati ben poco sulle cause di questa conservazione nei secoli; conservazione non soltanto riferita alle fabbriche ma, soprattutto, alle decorazioni. Tanto particolare da pensare che sia insolita. E anche se lo spirito della controriforma probabilmente ne spiegherebbe una parte, lascia comunque perplessi. Quei nuovi edifici cambiarono senza alcun dubbio la percezione della città sia dei romani che degli stranieri.

Dall'altro lato, c'è la città che cambia concettualmente. Sono diversi i testi scritti a proposito della grande traslatio di 2300 (duemillatrecento) corpi di martiri esumati nelle catacombe e nuovamente seppelliti dentro a Santa Prassede. Gli autori si chiedono da dove venissero, di che martiri si trattasse, chi fu il primo pontefice a infrangere la norma di sotterrare intra moenia, lo stato d'uso e conservazione delle catacombe... Molte di meno, quasi nessuna, sono invece le riflessioni sul cambio di concetto di città collegato all'adozione di questa soluzione. Di sicuro l'importanza del culto delle reliquie nel mondo franco ebbe un peso nella decisione di Pasquale I. Ed è vero anche che pontefici dell'VIII secolo avevano fatto piccole traslazioni creando così dei precedenti. Ciononostante, è vero anche che il colpo di scena di chi prese la decisione e l'affermazione di autorità che dimostra non sono da poco. Senz'altro servirono a ridefinire sia la figura del Papa di fronte ai franchi -fatto che si evince anche in altri passaggi della vita del pontefice, dalla firma del Hludovicianum allo scontro con Lotario I- e di fronte all'imperatore di Oriente -la lettera diretta a Leone IV sull'iconoclastia è un vero manifesto-, sia a ridefinire il ruolo di Roma, l'antica città imperiale, di fronte a Costantinopoli, la ormai vecchia nuova Roma fondata da Costantino I.

I testi che compongono questo numero monografico di SVMMA sono il risultato dell'incontro tenutosi a Roma il 17 e 18 novembre 2016 sotto il titolo «Grata più delle Stelle»S. Prassede e Pasquale I (817-824). Dialogo multidisciplinare intorno alla basilica e il suo papa, incontro che è servito per cominciare a dare forma ad alcune delle idee che durante parte del 2015 e tutto il 
2016 un primo nucleo di ricercatori -A. Ballardini, G. Bordi, M. Caperna, A. Verardi e colui chi sottoscrive queste righe- maturavano durante le visite agli edifici di Pasquale I.

Come conseguenza di quel primo incontro altri ricercatori si sono aggiunti $-\mathrm{S}$. Ammirati, R. Michetti, R. Santangeli Valenzani- dando forma, così, al Comitato scientifico del seminario permanente sulla figura di Pasquale I e la Roma del suo tempo che si svilupperà fra novembre 2017 e febbraio 2018, principalmente a Roma, organizzato dall'Università degli Studi Roma Tre, Sapienza-Università di Roma e l'Istituto di Ricerca in Culture Medievali (IRCVM) dell'Universitat de Barcelona.

Di fronte allo schema tradizionale, quindi, ci proponiamo, tramite seminari periodici, di discutere tranquillamente sull'importanza di questo pontefice e sulle conseguenze del suo operato nella città di Roma e nei suoi monumenti. Dopo anni di ricerca e discussione siamo convinti che questo sia il miglior modo per proporre risultati solidi a proposito di casi di studio altamente complessi.

Nel breve termine la pubblicazione di un volume con gli esiti di questi seminari, così come altre azioni ancora allo stato embrionale, consentiranno di conoscere l'importanza del momento storico e l'interpretazione che di esso dette il pontefice, elementi necessari per capire l'altomedioevo a Roma.

Come assaggio iniziale proponiamo i cinque contributi usciti da quel primo incontro, la finalità dei quali è presentare alcuni punti interrogativi ancora non risolti o non ancora affrontati nella ricerca su Pasquale I.

Un punto di partenza, quindi, per avviare il dibattito.

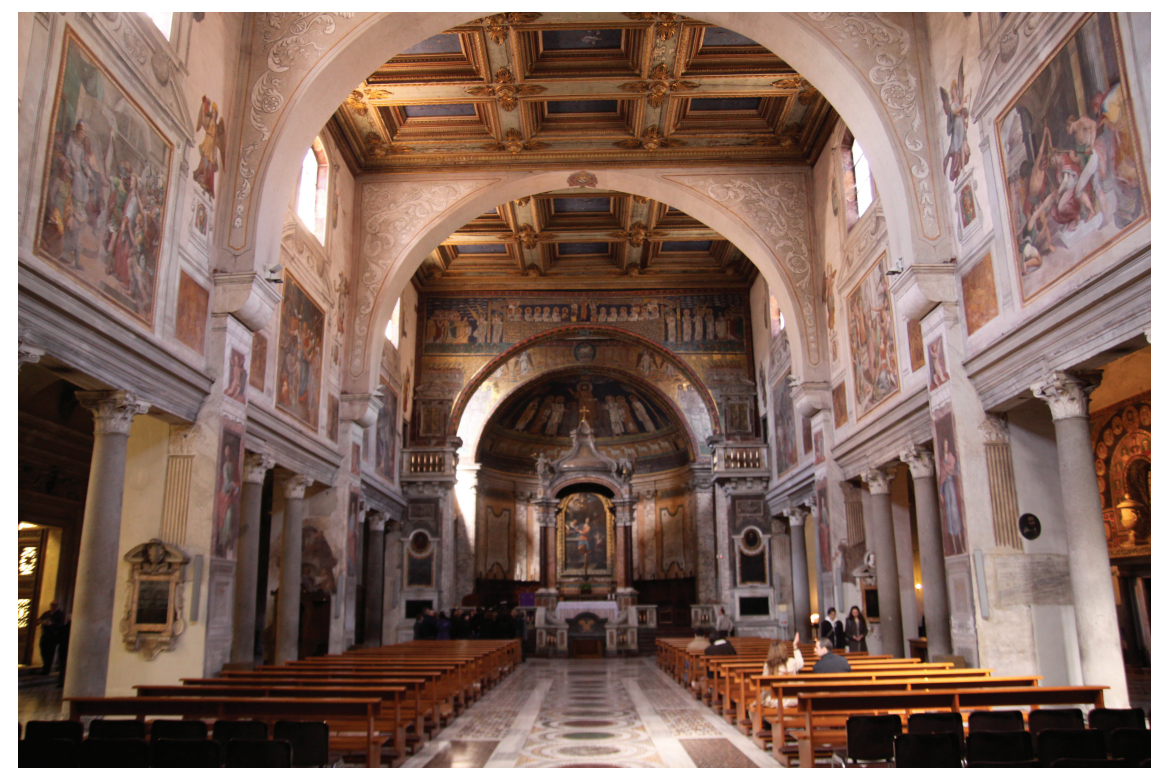

